\title{
First Example of a Continuous-Flow Carbonylation Reaction Using Aryl Formates as CO Precursors
}

\author{
Nerea Alonso ${ }^{1,3}$, Juan de M. Muñoz ${ }^{1}$, Brecht Egle ${ }^{2}$, Johannes L. Vrijdag², Wim M. De Borggraeve ${ }^{2 *}$, \\ Antonio de la $\mathrm{Hoz}^{3}$, Angel Díaz-Ortiz ${ }^{3}$ and Jesús Alcázar ${ }^{1 *}$ \\ ${ }^{1}$ Department of Medicinal Chemistry, Janssen Research and Development, Janssen-Cilag, S.A., C/Jarama 75, 45007 Toledo, Spain \\ ${ }^{2}$ University of Leuven, Department of Chemistry, Molecular Design and Synthesis, \\ Celestijnenlaan 200F, box 2404, BE3001 Heverlee, Belgium \\ ${ }^{3}$ Facultad de Ciencias y Tecnologías Químicas, Universidad de Castilla-La Mancha, 13071 Ciudad Real, Spain
}

Received: 18 February 2014; accepted: 18 March 2014

\begin{abstract}
The first continuous flow carbonylation reaction using aryl formates as $\mathrm{CO}$ precursor is reported. The reaction is practical, scalable and high yielding. The use of a flow protocol safely allows expanding the scope to activated chlorides, nitrogen heterocycles and to the selective introduction of an ester group in dihalo-derivatives. Further selective reduction of the ester formed to an aldehyde in flow is also described.
\end{abstract}

Keywords: CO-free, carbonylation, flow chemistry, aryl formate, palladium

\section{Introduction}

Palladium-catalyzed carbon monoxide-mediated carbonylation of aryl halides and pseudohalides is a key reaction in organic synthesis and in bulk chemical industry [1]. Despite its applicability, the difficulty in handling toxic, gaseous $\mathrm{CO}$, including its storage and transport, remains a serious safety concern and reduces the overall utility of the protocols. Therefore, the use of a precursor molecule able to release carbon monoxide under the reaction conditions is a highly desirable alternative [2]. Different CO sources have successfully been used in batch reactions: examples are metal carbonyl complexes [3], aldehydes [4], formamides [5], formic anhydrides [6], and more recently, aryl formates [7] and $\mathrm{N}$-formyl saccharin [8].

Flow chemistry has emerged as an enabling technology that allows accessing novel process windows [9]. Reactions can be performed under high temperature and pressure, usually above the boiling point of the solvent. This enables excellent control of reaction parameters and thereby often enhances selectivity [10]. Furthermore, the use of continuous-flow reactors contributes to sustainability as hazardous compounds can be better contained, and hence, in some cases, it reduces the amounts required of these dangerous chemicals [11]. Especially, this last feature, in view of the concerns mentioned earlier, offers possibilities when developing methodology involving $\mathrm{CO}$ and/or its precursors.

Carbonylation under continuous-flow conditions has been studied using an external carbon monoxide gas supply via different approaches. First, $\mathrm{CO}$ gas and reagent solution were intensively mixed inline, and this mixture was passed through a supported catalyst in a pressurized reactor [12]. Effective carbonylation was achieved, although high pressures of gas were required. Second, a more simple setup with a gas permeable tube-in-tube reactor can be used to deliver the $\mathrm{CO}$ in the reaction mixture. This setup allows using somewhat lower pressures of $\mathrm{CO}$ gas, which enhances the safety profile [13]. However, an external $\mathrm{CO}$ cylinder (with all related safety issues) is still required for this system. Another, more advanced alternative to this approach has been described recently where the gas is formed in situ by dehydration of formic acid with sulfuric acid [14]. This allowed the use of only a small excess of the toxic gas, but harsh acidic conditions are required to produce it, limiting the utility of the protocol. Despite all these

\footnotetext{
* Author for correspondence: wim.deborggraeve@chem.kuleuven.be and jalcazar@its.jnj.com
}

efforts, simple and effective scalable carbonylation protocols in flow without the use of an external CO gas supply have not been reported so far.

\section{Results and Discussion}

After an analysis of the different carbon monoxide sources, we considered aryl formates as potential precursors for use in continuous-flow chemistry. They are able to release CO under much milder conditions than, for example, formamides or aldehydes. They are also, unlike metal carbonyl complexes, well soluble in organic solvents, a clear advantage for flow reactions. Finally, they are less reactive than formic anhydrides.

Initially, the reaction was pre-optimized using a microwave reactor, as this technology has a similar process window as flow reactors (Table 1). In this way, reaction times could be shortened from several hours to minutes and solubility of reagents and final products was easily assessed to assure the protocol could be transferred to flow. This exploration was performed using bromobenzene as the substrate and 2,4,6-trichlorophenyl formate [7] as CO source. This precursor was selected because it releases $\mathrm{CO}$ under mild conditions. This formate can decompose efficiently at room temperature to give carbon monoxide and trichlorophenol when mixed with organic bases.

Using the batch conditions described in the literature as a starting point [7], the mixture was heated at different temperatures, keeping a fixed reaction time of $5 \mathrm{~min}$. At $140{ }^{\circ} \mathrm{C}$, the reaction proceeded with a very high conversion (entry 2 ), and by increasing the reaction time to $10 \mathrm{~min}$, the reaction was almost completed (entry 3). The base was changed to DIPEA, but a turbid crude mixture was obtained (entry 4). The use of phenyl formate as an alternative $\mathrm{CO}$ precursor clearly decreased conversion (entry 5), probably because its decomposition is slower compared to the corresponding trichloro analogue [7].

Other catalysts/ligands than those described in the literature were tried either in solid supported or soluble form (entries 6-11). However, none of them was superior to the reported $\mathrm{Pd}(\mathrm{OAc})_{2}-$ Xantphos system. Nevertheless, $\mathrm{Pd}\left(\mathrm{PPh}_{3}\right)_{4}$ behaved reasonably well in contrast to what is described for phenyl formate carbonylations under traditional heating, where the best results are usually obtained using specialized bidentate ligands [7]. Following this finding, the reaction was also attempted with a silica supported palladium diphenylphosphine catalyst, SiliaCat DPP-Pd, which we successfully used in previous continuous-flow cross-coupling 
Table 1. Optimization of model reaction under microwave irradiation in batch

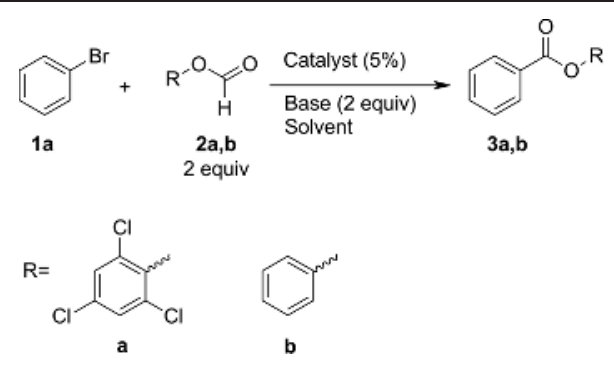

\begin{tabular}{|c|c|c|c|c|c|c|c|}
\hline Entry & Base & Formate & Catalyst & Solvent & $t / \min$ & $T /{ }^{\circ} \mathrm{C}$ & Conv. $(\%)^{a}$ \\
\hline 1 & $\mathrm{Et}_{3} \mathrm{~N}$ & $2 \mathbf{a}$ & $\mathrm{Pd}(\mathrm{OAc})_{2}-$ Xantphos & DMF & 5 & 120 & 29 \\
\hline 2 & $\mathrm{Et}_{3} \mathrm{~N}$ & $2 \mathbf{a}$ & $\mathrm{Pd}(\mathrm{OAc})_{2}-$ Xantphos & DMF & 5 & 140 & 87 \\
\hline 3 & $\mathrm{Et}_{3} \mathrm{~N}$ & $2 a$ & $\mathrm{Pd}(\mathrm{OAc})_{2}-$ Xantphos & DMF & 10 & 140 & 98 \\
\hline 5 & $\mathrm{Et}_{3} \mathrm{~N}$ & $2 b$ & $\mathrm{Pd}(\mathrm{OAc})_{2}-$ Xantphos & DMF & 10 & 140 & 64 \\
\hline 6 & $\mathrm{Et}_{3} \mathrm{~N}$ & $2 \mathbf{a}$ & $\mathrm{Pd}\left(\mathrm{PPh}_{3}\right)_{4}$ & DMF & 5 & 140 & 75 \\
\hline 7 & $\mathrm{Et}_{3} \mathrm{~N}$ & $2 \mathbf{a}$ & $\mathrm{PdCl}_{2}\left(\mathrm{PPh}_{3}\right)_{2}$ & DMF & 5 & 140 & 70 \\
\hline 8 & $\mathrm{Et}_{3} \mathrm{~N}$ & $2 \mathbf{a}$ & PEPPSI-Ipr & DMF & 5 & 140 & 5 \\
\hline 10 & $\mathrm{Et}_{3} \mathrm{~N}$ & $2 \mathbf{a}$ & SiliaCat DPP-Pd [15] & DMF & 5 & 140 & 10 \\
\hline 11 & $\mathrm{Et}_{3} \mathrm{~N}$ & $2 \mathbf{a}$ & SiliaCat DPP-Pd & $\mathrm{CH}_{3} \mathrm{CN}$ & 5 & 140 & 25 \\
\hline
\end{tabular}

Conditions: Bromobenzene $(0.475 \mathrm{mmol})$, formate ( 2 equiv.), and catalyst $(5 \mathrm{~mol} \%)$ were dissolved in $4 \mathrm{~mL}$ of solvent; the base $(2$ equiv.) was added, and this mixture was submitted to microwave irradiation for the indicated time and temperature.

${ }^{a}$ Conversions determined as percentage of product and remaining starting material by GC-MS.

${ }^{b}$ Turbid mixture.

chemistry [15]. However, conversion with this catalyst was low (entries 10 and 11) and it was not further considered for translation to flow conditions.

With all this information at hand, the reaction conditions were translated to a continuous-flow process [16]. In order to avoid premature (base induced) decomposition of the formate, two separate solutions were needed to feed into the flow reactor. Different combinations were evaluated to achieve this goal. The best combination proved to be the preparation of a first solution containing haloarene, palladium acetate, Xantphos, and triethylamine in a 1:1 dimethylformamide-tetrahydrofuran (DMF-THF) mixture and the second containing 2,4,6-trichlorophenyl formate in DMF. As high temperature and slightly elevated pressure were required, the most suitable instrument was the high temperature module from the Vapourtec R2+R4 reactor [17]. Reagent solutions were introduced via separate loops and mixed in a T-mixer before being introduced in the reactor at the desired conditions. As some palladium black particles were observed at the outlet of the reactor, a filter piece [18] was introduced to collect all particles and prevent clogging at the back pressure regulator (Figure 1).

Table 2 summarizes the optimization of reaction conditions for the continuous-flow process using the system described in Figure 1. Initial direct translation from microwave conditions to
Table 2. Transferring batch reaction conditions to flow

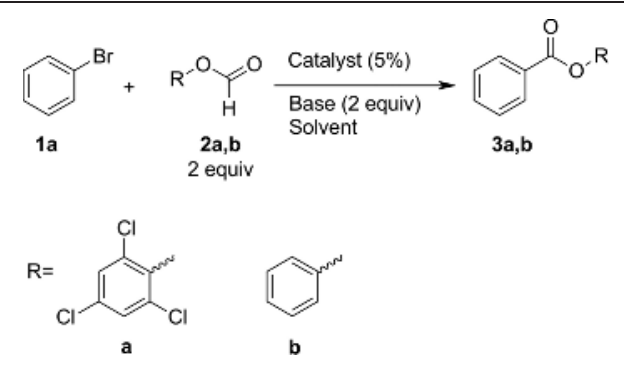

\begin{tabular}{lcccccc}
\hline Entry & 2a & $\mathrm{Et}_{3} \mathrm{~N}$ & $\begin{array}{c}\mathrm{Pd}(\mathrm{OAc})_{2} \\
(\mathrm{~mol} \%)\end{array}$ & $t_{\mathrm{R}} / \mathrm{min}$ & $T /{ }^{\circ} \mathrm{C}$ & ${\text { Conv. }(\%)^{a}}^{a}$ \\
\hline 1 & 2 equiv. & 2 equiv. & 5 & 10 & 140 & 92 \\
2 & 2 equiv. & 2 equiv. & 5 & 5 & 140 & 90 \\
3 & 2 equiv. & 2 equiv. & 5 & 5 & 150 & 97 \\
4 & 2 equiv. & 2 equiv. & 5 & 2.5 & 150 & 58 \\
5 & 1.3 equiv. & 1.3 equiv. & 5 & 5 & 150 & 95 \\
6 & 1.3 equiv. & 1.3 equiv. & 3 & 5 & 150 & 94 \\
7 & 1.3 equiv. & 1.3 equiv. & 1 & 5 & 150 & 80 \\
8 & 1 equiv. & 1 equiv. & 5 & 5 & 150 & 91
\end{tabular}

Conditions: Vapourtec R2+R4, 2-mL reactor loop, BPR 250 psi. Solution $\mathrm{A}$ : $\mathrm{Pd}(\mathrm{OAc})_{2}-\mathrm{Xantphos}(1: 2)$, bromobenzene $(0.24 \mathrm{M})$, and $\mathrm{Et}_{3} \mathrm{~N}$ in $1: 1$ DMF-THF; solution B: 2a in DMF.

${ }^{a}$ Conversions determined as percentage by GC-MS.

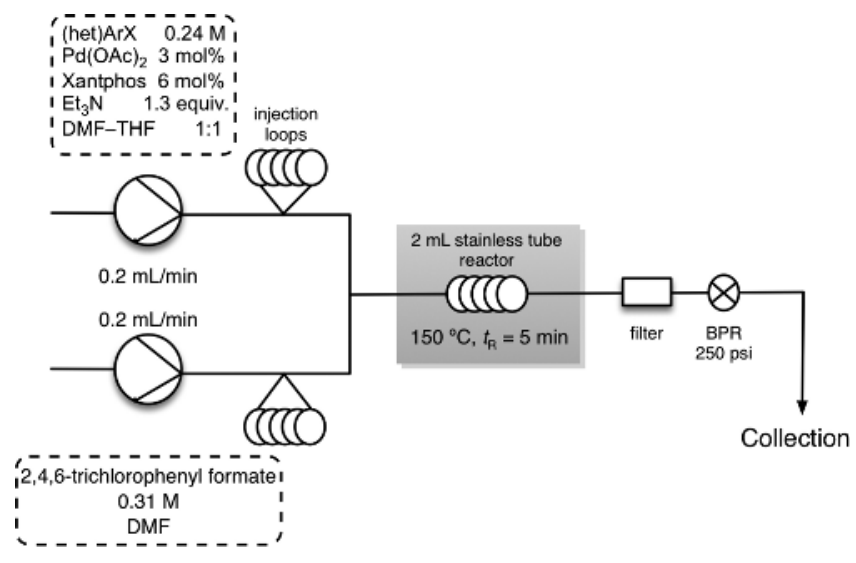

Figure 1. Experimental setup of the flow system 
Scheme 1. Reaction scope

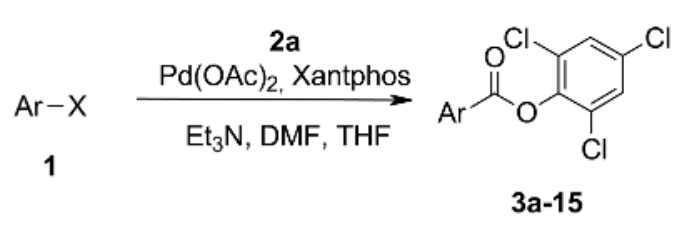<smiles>O=C(Oc1c(Cl)cc(Cl)cc1Cl)c1ccccc1</smiles>

3a

$\mathrm{X}=\mathrm{Cl}$, no reaction

$\mathrm{X}=\mathrm{Br}, \quad 93 \%$

$X=1, \quad 99 \%$

$X=$ OTf, $81 \%$<smiles>CCc1ccc(C(=O)Oc2c(Cl)cc(Cl)cc2Cl)cc1</smiles>

$\mathrm{X}=\mathrm{Br}, 86 \%$<smiles>N#Cc1ccc(C(=O)Oc2c(Cl)cc(Cl)cc2Cl)cc1</smiles>

$\mathrm{X}=\mathrm{Br}, 99 \%$<smiles>O=C(Oc1c(Cl)cc(Cl)cc1Cl)c1ccccn1</smiles>

$\mathrm{X}=\mathrm{Br}, 98 \%$ $\mathrm{X}=\mathrm{Cl}, 57 \%$<smiles>Cn1cc(C(=O)Oc2c(Cl)cc(Cl)cc2Cl)cn1</smiles>

$X=B r, 43 \%$<smiles>Cn1cncc1C(=O)Oc1c(Cl)cc(Cl)cc1Cl</smiles>

$\mathrm{X}=\mathrm{Br}, 90 \%$<smiles>O=C(Oc1c(Cl)cc(Cl)cc1Cl)c1cccnc1</smiles>

9

$\mathrm{X}=\mathrm{Br}, 99 \%$<smiles>COC(=O)c1ccc(C(=O)Oc2c(Cl)cc(Cl)cc2Cl)cc1</smiles>

$\mathrm{X}=\mathrm{Br}, 94 \%$<smiles>O=C(Oc1c(Cl)cc(Cl)cc1Cl)c1ncccn1</smiles>

11<smiles>O=C(Oc1c(Cl)cc(Cl)cc1Cl)c1ccsc1</smiles>

12<smiles>O=C(Oc1c(Cl)cc(Cl)cc1Cl)c1cncnc1</smiles>

13

$\mathrm{X}=\mathrm{Br}, 84 \%$ $\mathrm{X}=\mathrm{Br}, 91 \%$ $\mathrm{X}=\mathrm{Br}, 91 \%$<smiles>O=C(Oc1c(Cl)cc(Cl)cc1Cl)c1ccc(Br)cc1</smiles>

$X=I, 91 \%$<smiles>O=C(Oc1c(Cl)cc(Cl)cc1Cl)c1cscc1Br</smiles>

$\mathrm{X}=\mathrm{Br}, 65 \%$

$\mathrm{X}=\mathrm{Br}, 81 \%^{\mathrm{a}}$

Conditions: Vapourtec R2+R4, 2-mL reactor loop, 5 min residence time, BPR 250 psi, $150{ }^{\circ} \mathrm{C}$. Solution A: Aryl halide $(0.24 \mathrm{M})$, Pd(OAc) 2 (3 mol\%), Xantphos (6 mol\%), and $\mathrm{Et}_{3} \mathrm{~N}\left(0.31 \mathrm{M}, 1.3\right.$ equiv.) in $1: 1 \mathrm{DMF}-\mathrm{THF}$; solution $\mathrm{B}: 2 \mathrm{a}(0.31 \mathrm{M})$ in DMF. ${ }^{\mathrm{a}}$ Reaction performed at $170{ }^{\circ} \mathrm{C}$

flow worked well as expected (Table 1, entry 2; and Table 2, entry 2). However, it was observed that, under flow conditions, increasing the temperature by $10{ }^{\circ} \mathrm{C}$ was more efficient than extending the retention time by 5 min (entries 1 and 3 ). Although, initially, 2 equivalents of $\mathrm{CO}$ precursor were required in batch conditions, it could be reduced to 1.3 equivalents under flow conditions (entry 5). A further reduction of the number of equivalents decreased the observed conversion (entry 8). Similarly, the amount of palladium could be reduced to $3 \%$ (entries 6 and 7).

The optimized conditions (Table 2, entry 6) were then used to explore the scope of the reaction (Scheme 1). Bromides, iodides, and trifluoromethanesulfonate derivatives are suitable substrates for the reaction. Chlorobenzene did not react under these conditions, whereas 2-chloropyridine gave the expected carbonylated product $\mathbf{6}$ in an acceptable yield. This is the first example of the application of aryl formate carbonylation to this class of compounds.

The reaction displays a broad applicability, and both electrondonating and withdrawing groups are tolerated (compounds $\mathbf{4}$,
5, and 10). Furthermore, the methodology could be successfully applied to various heterocyclic substrates, recurring scaffolds in medicinal chemistry. The continuous-flow protocol was efficient for carbonylation of both $\pi$-electron deficient (compounds 6, 9, 11, and 13) and $\pi$-electron rich heterocycles (compounds 7, 8, 12, and 15).

Selective introduction of substituents is a well-known advantage that flow procedures offer over traditional batch approaches [10]. Taking into consideration that the reaction could be performed with almost equimolar amounts of carbonylating agent, it was worth exploring the chemoselectivity of the reaction. In this way, compound $\mathbf{1 4}$ was obtained after a selective iodide replacement. Moreover, 3,4-dibromothiophene reacted selectively on one of the bromine atoms, providing the monoester derivative $\mathbf{1 5}$ in good yield when the reaction temperature was increased to $170{ }^{\circ} \mathrm{C}$. This result is remarkable as all previously reported dibromo and diiodo derivatives in batch always yielded the corresponding diester products [7].

Another important advantage of flow chemistry is the straightforward scalability of the protocols [10]. In order to explore the 
Scheme 2. Selective reduction of trichloro phenyl ester ${ }^{\mathrm{a}}$
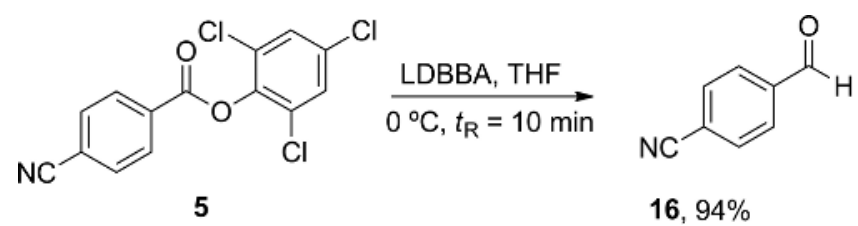

${ }^{\mathrm{a} C}$ Conditions: Vapourtec R2+R4, 5-mL reactor loop, residence time: 5 min, $0{ }^{\circ} \mathrm{C}$. Solution A: 5 (1 equiv., $\left.0.455 \mathrm{M}\right)$ in THF; solution B: LDBBA (1.1 equiv., $0.5 \mathrm{M}$ ) in hexane-THF

scalability of the procedure, compound $\mathbf{1 5}$ was selected as the most interesting example. Two stock solutions were prepared, but a slow decomposition of the trichlorophenyl formate in DMF was observed, presumably due to the presence of traces of free dimethyl amine in the solvent [19]. This impaired the performance of the instrument as gas bubble formation compromises stable pumping rates. To overcome this issue, the scale-up process was instead performed using two $10-\mathrm{mL}$ loops that were fed with freshly prepared solutions as in the previous small scale experiments. Because the loops are placed between two check valves, the solutions are pressurized, which inhibits bubble formation. Once these solutions have passed through the reactor at $170{ }^{\circ} \mathrm{C}$, two new solutions were fed again into the loops by changing valve positions without stopping the whole system. Using this approach, $3 \mathrm{~g}$ of compound 15 was obtained ( $82 \%$ yield), proving the scalability of the flow reaction.

Transformation of the trichlorophenyl ester into different functional groups has already been reported in batch [7c]. These protocols include the transformation of the phenyl ester products into alkyl esters, thioesters, amides (including Weinreb amides), and carboxylic acids. Surprisingly, reduction of these phenyl esters remained unreported. Partial reduction of esters to aldehydes is an interesting and challenging transformation in organic chemistry. In a recent article, we have described the use of lithium diisobutyl-tert-butoxy-aluminium hydride (LDBBA) in flow to perform this transformation in a selective manner [20]. Due to the incompatibility of the reducing agent with the solvent and the presence of trichlorophenol, both reactions could not be cascaded in the same line. Therefore, isolation of the carbonylated product was required to perform this second step. Compound $\mathbf{5}$ was selected to try this selective reduction as it presents two different functionalities suitable to be reduced, the ester and the cyano groups (Scheme 2). It could be selectively reduced indeed to the aldehyde $\mathbf{1 6}$ under standard conditions, proving the value of the combination of the two flow reactions to obtain aldehydes from halo derivatives in high yield.

\section{Conclusions}

In summary, a continuous-flow protocol for carbonylation of (pseudo)haloarenes using aryl formates as $\mathrm{CO}$ precursors has been reported for the first time. It allows performing carbon monoxide coupling reactions in a mild and safe way, reducing the amount of free toxic gas to almost equimolecular amounts. The reaction presents a wide applicability and is compatible with the presence of different functional groups as well as various heterocycles. The generalized use of chloroarenes remains a current limitation of the protocol; however, carbonylation of 2-chloropyridine was successfully achieved by our procedure. Other advantages of the flow protocol include the carbonylation of electron rich 5-membered heterocycles, such as imidazole and pyrazole, as well as the improved selectivity when using dihalo derivatives. The esters formed can be transformed in other interesting functional groups, such as aldehydes, by applying a subsequent, selective reduction in flow. Further explorations to overcome the current limitations of the reaction are ongoing and will be presented in future articles.

\section{Experimental}

4.1. General Procedure for Reactions under ContinuousFlow Conditions. Two solutions, $\mathrm{Pd}(\mathrm{OAc})_{2}(3 \mathrm{~mol} \%)$, Xantphos $(6 \mathrm{~mol} \%)$, halide (1 equiv., $0.24 \mathrm{M})$, and $\mathrm{Et}_{3} \mathrm{~N}$ (1.3 equiv.) in THF$\operatorname{DMF}(1: 1)$ and 2,4,6-trichlorophenyl formate (1.3 equiv., $0.31 \mathrm{M})$ in DMF were each pumped at $0.2 \mathrm{~mL} / \mathrm{min}$ using the $\mathrm{R} 2+\mathrm{R} 4$ system. The mixed solution was driven to a $2-\mathrm{mL}$ coil at $150{ }^{\circ} \mathrm{C}$, $t_{\mathrm{R}}=5 \mathrm{~min}$. The outlet solution was concentrated in vacuo, and the residue was purified by silica gel column chromatography.

Acknowledgements. The authors express their appreciation to Dr. L. M. Font and Dr. K. Van Emelen for their collaboration in the preparation of this article. The authors also acknowledge the funding provided by the Spanish Ministerio de Ciencia e Innovación (project CTQ2011-22410). B.E. and J.L.V. thank the Research Foundation - Flanders (FWO) for PhD fellowships. B.E., J.L.V., and W.M.D.B. also thank KU Leuven for financial support via project OT/11/047.

\section{Supporting Information}

Electronic Supplementary Material (ESM) on experimental procedures, expanded set of experiments, and analytical data is available in the online version at doi:10.556/JFC-D-14-00005.

\section{References}

1. (a) Brennführer, A.; Neumann, H.; Beller, M. Angew. Chem., Int. Ed. 2009, 48, 4144; (b) Brennführer, A.; Neumann, H.; Beller, M. ChemCatChem 2009, 1, 28; (c) Kiss, G. Chem. Rev. 2001, 101, 3435; (d) Ali, B. E.; Alper, H. Transition Met. Org. Synth.; (e) Beller, M.; Bolm, C., Ed.; Wiley-VCH: Weinheim; 1998, 49; (f) Colquhoun, H. M.; Thompson, D. J.; In Carbonylation: Direct Synthesis of Carbonyl Compounds; Twigg, M. V., Ed.; Plenum: New York, 1991; 119.

2. Morimoto, T.; Kakiuchi, K. Angew. Chem., Int. Ed. 2004, 43, 5580.

3. Wieckowska, A.; Fransson, R.; Odell, L. R.; Larhed, M. J. Org. Chem. 2011, 76, 978 .

4. (a) Morimoto, T.; Fuji, K.; Tsutsumi, K.; Kakiuchi, K. J. Am. Chem. Soc. 2002, 124, 3806; (b) Shibata, T.; Toshida, N.; Takagi, K. Org. Lett. 2002, 4, 1619; (c) Morimoto, T.; Yamasaki, K.; Hirano, A.; Tsutsumi, K.; Kagawa, N.; Kakiuchi, K.; Harada, Y.; Fukumoto, Y.; Chatani, N.; Nishioka, T. Org. Lett. 2009, 11, 1777.

5. (a) Hosoi, K.; Nozaki, K.; Hiyama, T. Org. Lett. 2002, 4, 2849; (b) Wan, Y.; Alterman, M.; Larhed, M.; Hallberg, A. J. Org. Chem. 2002, 67, 6232; (c) Ko, S.; Lee, C.; Choi, M.-G.; Na, Y.; Chang, S. J. Org. Chem. 2003, 68, 1607. 6. Cacchi, S.; Fabrizi, G.; Goggiamani, A. J. Comb. Chem. 2004, 6, 692. 7. (a) Fujihara, T.; Hosoki, T.; Katafuchi, Y.; Iwai, T.; Terao, J. Tsuji, Y Chem. Commun. 2012, 48, 8012; (b) Ueda, T.; Konishi, H.; Manabe, K. Org. Lett. 2012, 14, 3100; (c) Ueda, T.; Konishi, H.; Manabe, K. Org. Lett. 2012, 14 , 5370 .

8. (a) Ueda, T.; Konishi, H.; Manabe, K. Angew. Chem., Int. Ed. 2013, 52 , 8611; (b) Ueda, T.; Konishi, H.; Manabe, K. Org. Lett. 2013, 15, 5370

9. Hessel, V.; Kralisch, D.; Kockmann, N.; Nöel, T.; Wang, Q. ChemSusChem 2013, 6, 746 .

10. (a) Microreactors: New Technology for Modern Chemistry; Ehrfield, W.; Hessel, V.; Löwe, H., Ed.; Wiley-VCH: Weinheim, 2000; (b) Wiles, C.; Watts, P. Eur. J. Org. Chem. 2008, 1655; (c) Illg, T.; Löb, P.; Hessel, V. Bioorg. Med. Chem. 2010, 18, 3707; (d) Watts, P.; Haswell, S. J. Drug Discovery Today 2003, 8, 586; (e) Microreactors in Organic Synthesis and Catalysis; Wirth T., Ed.; Wiley-VCH: Weinheim, 2008; (f) Mason, B. P.; Price, K. E.; Steinbacher, J. L.; Bogdan, A. R.; McQuade, D. T.; Chem. Rev. 2007, 107, 2300; (g) Sahoo, H. R.; 
Kralj, J. G.; Jensen, K. F. Angew. Chem., Int. Ed. 2007, 46, 5704; (h) Hartman, R. L.; McMullen, J. P.; Jensen, K. F. Angew. Chem., Int. Ed. 2011, 50, 7502; (i) Baxendale, I. R.; Griffiths-Jones, C. M.; Ley, S. V.; Tranmer, G. K. Synlett 2006 427.

11. (a) Wiles, C.; Watts, P. Green Chem. 2012, 14, 38; (b) Ley, S. V. Chem Rec., 2012, 12, 378

12. Csajági, C.; Borcsek, B.; Niesz, K.; Kovács, I.; Székelyhidi, Z.; Bajkó, Z.; Ürge, L.; Darvas, F. Org. Lett. 2008, 10, 1589

13. Koos, P.; Gross, U.; Polyzos, A.; O’Brien, M.; Baxendale, I.; Ley, S. V. Org. Biomol. Chem. 2011, 9, 6903.

14. Brancour, C.; Fukuyama, T.; Mukai, Y.; Skrydstrup, T.; Ryu, I. Org. Lett. 2013, 15, 2794

15. For further information about SiliaCat catalysts, visit the web: http:// www.silicycle.com. Recent references for the use of this catalyst in flow: (a) Munoz, J. de M.; Alcazar, J.; de la Hoz, A.; Diaz-Ortiz, A. Adv. Synth. Catal. 2012, 354, 3456; (b) Egle, B.; Muñoz, J. de M.; Alonso, N.; De
Borggraeve, W.M.; de la Hoz, A.; Díaz-Ortiz, A.; Alcázar, J. J. Flow. Chem. 2014, 4, 22

16. The following reference exemplifies translation of microwave conditions to flow: Damm, M.; Glasnov, T. N.; Kappe, C. O. Org. Process Res. Dev. 2010 , 14,215

17. For further information about Vapourtec flow reactors, visit the web: http://www.vapourtec.co.uk.

18. An empty 70-mm CatCart cartridge from Thalesnano was used as filter For further information about CatCart cartridges, visit the web: http://thalesnano. com/products/CatCart-and-compatible-system.

19. CAUTION: Care should be taken when preparing stock solutions of trichlorophenyl formate. The quality of DMF used is important as small amounts of base can induce $\mathrm{CO}$ formation, even at room temperature. It is recommended to first assess the stability of the precursor in a particular batch of solvent.

20. Muñoz, J. de M.; Alcázar, J.; de la Hoz, A.; Díaz-Ortiz, A. Eur. J. Org. Chem. 2012, 260 . 